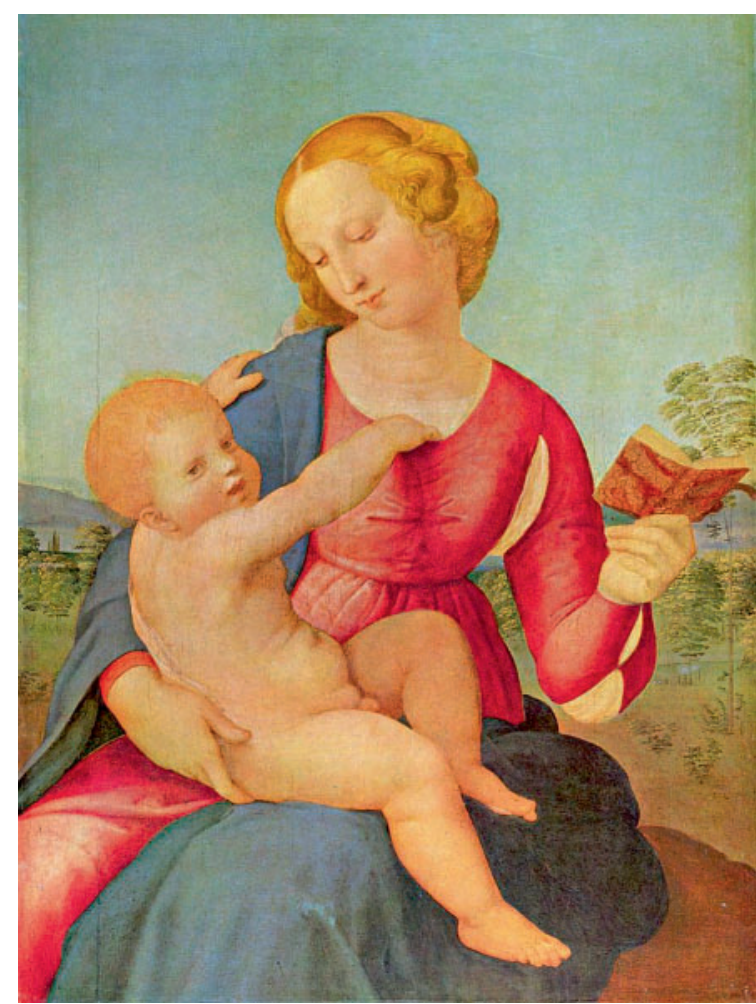

"Mich dürstet». Raffael: Die Madonna des Hauses Colonna.

\section{Liebe und Hunger}

Es ist wie ein Rendezvous: "An der Frauenbrust treffen sich Liebe und Hunger». Der verheißungsvolle Satz findet sich in Sigmund Freuds Jahrhundertwerk "Die Traumdeutung". Freud analysiert einen eigenen Traum. Er schickt dem Satz die Erzählung von der Traumgestalt einer "Wirtin» voraus: Sie ist "die Mutter, die das Leben gibt, mitunter auch, wie bei mir, dem Lebenden die erste Nahrung». Und er lässt die anekdotische Erzählung

Zum Autor: Ludger Lütkehaus, geb. 1943. Prof. Dr. phil., Universität Freiburg, Deutsches Seminar. Gastprofessuren in Atlanta, Siegen, Madison. 1979 Sonderpreis der Schopenhauer-Gesellschaft, 1996 Preis für Buch und Kultur, 1997 Max Kade Distinguished Visiting Professor an der University of Wisconsin-Madison, 2007 Robert-Mächler-Preis. Mitglied des PEN-Zentrums. Ständiger Mitarbeiter der "Zeit", der NZZ, deutscher, österreichischer und schweizer Rundfunk- und Fernsehanstalten, Juror der SachbuchBestenliste von NDR und SZ. von einem «jungen Mann» folgen, «der ein großer Verehrer der Frauenschönheit wurde". "Als die Rede auf die schöne Amme kam, die ihn als Säugling genährt", äußerte er einmal: "es tue ihm leid, die gute Gelegenheit damals nicht besser ausgenützt zu haben». "Für das Kind», bestätigt Freud, «ist der Busen der Amme tatsächlich das Einkehrwirtshaus" - der Busen der Wirtin-Mutter nicht weniger. Die Lust wie Nahrung spendende Dreifaltigkeit von Mutter, Amme, Wirtin erfreut gleichermaßen die frühkindliche wie die jungmännliche Trinkerbiographie.

Deswegen können sich später auch die Bilder der gestillten Triebbedürfnisse auf das schönste gleichen. "Wer ein Kind gesättigt von der Brust zurücksinken sieht, mit geröteten Wangen und seligem Lächeln in Schlaf verfallen", bekräftigt Freud in den "Drei Abhandlungen zur Sexualtheorie», "der wird sich sagen müssen, dass dieses Bild auch für den Ausdruck der sexuellen Befriedigung im späteren Leben maßgebend bleibt». Schwer zu sagen zwar, bei wem Freud den "Ausdruck der sexuellen Befriedigung" - gerötete Wangen und selig-lächelndes Verfallen in Schlaf post satisfactionem - beobachtet hat; aber zweifellos handelt es sich um ein doppelt befriedigendes Bild.

Um so mehr mag man das Bedauern des «jungen Mannes» teilen, seinerzeit «die gute Gelegenheit ... nicht besser ausgenützt zu haben». Immerhin hat er, der einst pars pro toto nach der vorherrschenden seiner Aktivitäten ein "Säugling" war, ohne dass man auf dieser frühen Stufe der Oralität schon zwischen der Stillung von Hunger und Durst unterscheiden müsste, die "gute Gelegenheit" damals wenigstens etwas ausgenützt. Und das ist auch gut so. Denn nach Freuds Studie «Eine Kindheitserinnerung des Leonardo da Vinci» handelt es sich um nichts Geringeres als "unseren ersten Lebensgenuss", um eine Situation, "in welcher wir uns einst alle behaglich fühlten» - "wir alle», die weiblichen Säuglinginnen nicht anders als die männlichen Säuglinge. Von der Favorisierung der «jungen Männer» in Freuds Traumerzählung ist auf der Urszene des Säugens und Saugens noch keine Rede. Deswegen kann Freud generell formulieren: "Das erste erotische Objekt des Kindes ist die ernährende Mutterbrust, (...) bei beiden Geschlechtern".

Gleichwohl ist nicht zu dementieren, dass primär der «junge Mann» Sigmund spricht - «a portrait of the analyst as a young man" -, wenn er in immer wieder neu angestimmten Lobgesängen, in wahren Hymnen der Oralität, das Rendezvous von Hunger und Liebe, den Reim von "Lust" auf "Brust» feiert. "Wenn der Säugling sich äußern könnte» - kann er das denn etwa nicht? - "würde er gewiss den Akt des Saugens an der Mutterbrust als das weitaus Wichtigste im Leben anerkennen. Er hat für sich nicht so unrecht, denn er befriedigt durch diesen Akt in einem beide großen Lebensbedürfnisse. (...)

\section{KARGER}

(C) 2007 S. Karger GmbH, Freiburg

Fax +497614520714 
Das Saugen an der Mutterbrust wird der Ausgangspunkt des ganzen Sexuallebens, das unerreichte Vorbild jeder späteren Sexualbefriedigung, zu dem die Phantasie in Zeiten der Not oft genug zurückkehrt". "In diesen beiden Relationen" - denen von Hunger und Liebe - «wurzelt die einzigartige, unvergleichliche, fürs ganze Leben unabänderlich festgelegte Bedeutung der Mutter als erstes und stärkstes Liebesobjekt, als Vorbild aller späteren Liebesbeziehungen»: oraler Determinismus.

Das sagt im "Abriss der Psychoanalyse" der späte Freud, der an seine frühen Traumerzählungen anschließt, aber inzwischen auch explizit die präödipale Beziehung des Säuglings zur Mutter entdeckt hat. Und damit ändert sich das Szenario der Triebpsychologie gravierend: Freud relativiert sowohl seine Lehre vom unvermeidlichen "Unbehagen in der Kultur» wie die vom ebenso unvermeidlichen Dualismus der "großen Lebensbedürfnisse", von Libido und Selbsterhaltung, Sexual- und Ichtrieben. Der nur allzu oft als Pessimist verschrieene Freud mit seinem unfreiwillig selbstironischen Namen; jener Freud, der als eine Art von Anti-Moses nur ins ungelobte Land «Jenseits des Lustprinzips» zu führen scheint, findet sich unversehens auf der Seite des Behagens in der Triebkultur, diesseits des Frustprinzips wieder. In der Wüste der Entbehrung eröffnet das Rendezvous von Hunger und Liebe an der Frauenbrust eine Oase doppelten frühen Glücks, das sich im Gegensatz zum sonst herrschenden Antagonismus von Sexual- und Ich-Trieben ihrer Verbindung verdankt. Die Frauenbrust ist insofern der Syntheseort schlechthin. Mit einem Wort: Wir befinden uns im oralen Paradies. Drücken wir es mit den Begriffen Horazischen Poetik aus, die bekanntlich die Synthese des "prodesse" mit dem «delectare», des Nützens mit dem Vergnügen vertritt, so kommt auch in der Einheit von «delectare" und "delactare», Erfreuen und Stillen, das Nützliche, Lebenserhaltende mit dem Angenehmen zusammen. Man kann es gut verstehen, wenn Freud darüber zum Hymniker der Oralität wird.

Der literarische und philosophische Kronzeuge des Triebtheoretikers Freud aber ist ausgerechnet der vermeintliche Idealist Friedrich Schiller. Von ihm, der uns sonst vergeblich die "Milch der frommen Denkart" einzuflößen versucht, die schon seinem
Wilhelm Tell zu "Drachengift» vergärt, hat Freud, bildungsbelesen und zitierfreudig wie stets, die Verbindung von Hunger und Liebe übernommen. In Schillers Gedicht "Die Weltweisen" - das sind in der Sprache der Aufklärung die Philosophen heißt es im Anschluss an die sarkastische Abfertigung der metaphysischen Moralsysteme, die lehren, dass der "Plan der Welt" mit ihnen anfangen solle:

«Doch weil, was ein Professor spricht,/ Nicht gleich zu allen dringet,/ So übt Natur die Mutterpflicht/ Und sorgt, dass nie die Kette bricht/ Und dass der Reif nie springet./ Einstweilen, bis den Bau der Welt/ Philosophie zusammenhält,/ Erhält sie das Getriebe/ Durch Hunger und durch Liebe.»

Einerseits nennt Schiller, anders als Freud, nicht den Ort, an dem sich Hunger und Liebe treffen: die Frauenbrust. Andererseits stellt er den kruderen "Hunger» der poetischeren "Liebe» voran. Insofern ist sein Programm ironischerweise realistischer als das Freudsche. Freud wiederum verzichtet auf jede Geschichtsphilosophie. Freilich ist auch das «einstweilen" Schillers, dessen Doppelstrategie der "Natur" mit ihren beiden Agenten Hunger und Liebe die vorphilosophische Stabilisierung des Weltbaus anvertraut, bevor Philosophie als Macht der Trieberübrigung diese Aufgabe übernimmt, als ironisches Understatement zu hören. Dieses «Einstweilen" pflegt hienieden zu dauern - natürlich nur einstweilen.

Bei Schiller wie bei Freud aber sind Hunger und Liebe die Triebe im "Getriebe». Bei Schiller wie bei Freud nimmt Mutter Natur mit Hunger und Liebe ihre mütterliche Doppelbestimmung wahr, für die Erhaltung und den libidinösen Zusammenhalt ihrer Kinder zu sorgen. Das Zitat des sakrosankten "Dichterphilosophen" mit seinem "respektablen Kräftepaar" autorisiert einmal Freuds doppelte Trieblehre von den Selbsterhaltungs- und Sexualtrieben - das ist die Zitatfunktion, die zunächst dominiert. Zugleich aber feiert er mit Schiller im Zeichen von Hunger und Liebe jene Synthese, von der sein Triebdualismus sonst nichts wissen will. Freud wie Schiller erfreuen sich einer "Denkart», die sowohl dem Realismus wie auch einer doppelten Befriedigung zugeneigt ist.

Ludger Lütkehaus

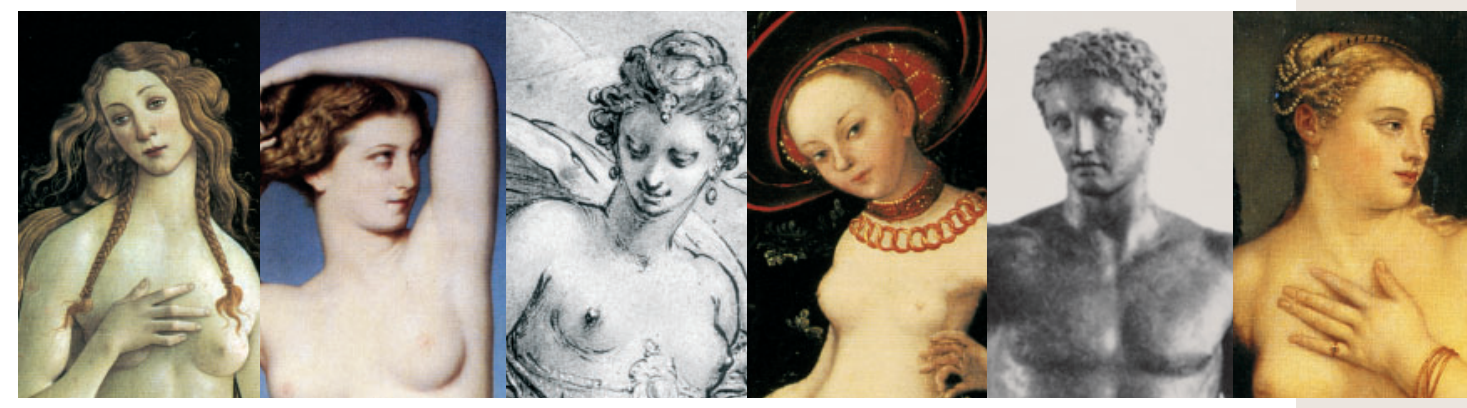

